\title{
Modification of poly-HEMA with nonreactive POSS derivatives by in situ photopolymerization
}

\author{
Agnieszka Marcinkowska ${ }^{1}$ (D) Dawid Przadka ${ }^{1} \cdot$ Ewa Andrzejewska $^{1}$
}

Received: 8 May 2018 / Accepted: 7 March 2019/Published online: 23 March 2019

(C) The Author(s) 2019

\begin{abstract}
Photo-induced polymerization of 2-hydroxyethyl methacrylate (HEMA) in the presence of various amounts of nonreactive polyhedral oligomeric silsesquioxanes (POSS) functionalized with glycidyl, fluoroalkyl or hydroxyl groups was investigated. HEMA/POSS systems were characterized before, during and after the photocuring, with the special emphasis on the photopolymerization kinetics (measured by isothermal differential scanning calorimetry). It was found that the introduction of tested POSS derivatives into HEMA strongly affects the photopolymerization kinetics (enhancement of the gel effect, increase in the polymerization rate and conversion), mainly due to the increase in the viscosity of the initial formulation which leads to a reduction in the termination rate coefficient. However, interactions HEMA-POSS cause also a slight increase in the propagation rate coefficient. The behavior of the polymerization rate coefficients during the reaction suggests that POSS cages may mitigate the inhibitory effect of viscosity on the diffusion of macroradicals by exerting a slip effect. The materials produced are microcomposites due to the partial phase separation occurring during the curing process. Small amounts of added POSS modifiers cause plasticization of the material; at higher loads, POSS domains behave like nanofiller aggregates that increase the glass temperature. The nonreactive POSS have very little effect on thermal decomposition of the poly-HEMA matrix, which can result in a degree from the phase separation; the latter is also the main cause of the deterioration of the mechanical properties of composites compared to a pure polymer matrix.
\end{abstract}

Keywords Polyhedral oligomeric silsesquioxanes - Methacrylates $\cdot$ Photopolymerization kinetics $\cdot$ DSC $\cdot$ Polymer composites

\section{Introduction}

In recent years, there has been a significant increase in interest in organic-inorganic materials with improved properties. They can be prepared by filling a polymer matrix with inorganic particles (also organically modified) to form nanocomposites or by chemical incorporation of such particles into the polymer matrix (hybrid polymer). Especially, interesting class of this type of modifiers is polyhedral oligomeric silsesquioxanes (POSS) with the general formula $\left(\mathrm{RSiO}_{1.5}\right)_{\mathrm{n}}$ where $\mathrm{R}$ is an organic functional group [1]. These organic substituents may contain

Agnieszka Marcinkowska

Agnieszka.Marcinkowska@put.poznan.pl

1 Institute of Chemical Technology and Engineering, Poznan University of Technology, Berdychowo 4, 60-965 Poznan, Poland reactive groups able to copolymerize with monomers, or nonreactive groups improving the miscibility with polymers. It should be emphasized that POSS compounds are not nanoparticles, but molecules, are soluble and can be dispersed in a polymer matrix on a molecular level [2]. However, during polymerization or processing, they tend to agglomerate, which leads to the formation of (nano)composites. Incorporation of POSS derivatives to the polymer matrix can significantly improve/affect its mechanical properties (e.g., strength, modulus, rigidity) as well as increase thermal stability and flame resistance or reduce the viscosity during processing. These improvements apply to a wide range of thermoplastics and thermosettings polymers [3]. Polymer/POSS composites can be used in such areas as bioimaging, shape memory materials, photonics, dielectrics, batteries, antireflective coatings, superhydrophobic surfaces, tissue scaffolding, nanolithography, 
biomedical adhesives, drug delivery or flame-retardant materials [4].

POSS-containing materials can be prepared using ex situ (blending POSS with polymers [5-7]) or in situ (by curing the monomer/POSS mixture [7, 8]) methods. In situ methods usually allow for a better dispersion of the modifier in the polymer matrix. When a material containing POSS is prepared by polymerizing a monomer containing dissolved POSS, it becomes very important to know the curing kinetics, because they determine to a large extent the properties of the material, provide information on the optimal proportions of the monomer/modifier ratios and allows the selection of technological parameters of curing.

A particularly interesting method of curing is photopolymerization. The most important advantages of this technique are: very high speed of the reaction, ambient reaction temperature, high control of the reaction (the start and end points are well defined by lighting on/off) or spatial control (the reaction takes place only in irradiated areas) $[9,10]$. These advantages of photopolymerization make it an attractive method of designing and developing of new materials.

In our previous work [11], we studied materials produced in UV-initiated copolymerization of 2-hydroxyethyl methacrylate (HEMA) with octamethacryloxy-POSS (MPOSS); both the kinetics of the reaction and the properties of the obtained materials were discussed. The use of POSS functionalized with methacryloxy groups led to the formation of a hybrid polymer; the polymerization kinetics and polymer properties were influenced not only by the physical interactions between the POSS modifier and the monomer or matrix (before and after UV curing), but also the formation of a polymer network. In the present work, we excluded the effect of network formation by using POSS-containing substituents that are not reactive in radical polymerization. The systems were characterized before, during and after the photocuring, with the special emphasis on the photopolymerization kinetics. The reaction kinetics were followed by isothermal differential scanning calorimetry (DSC), because this method is especially useful for studying the UV-initiated polymerization [9].

\section{Experimental}

\section{Materials}

Monomer: 2-hydroxethyl methacrylate (HEMA, purity 97\%) and photoinitiator: 2,2-dimethoxy-2-phenylacetophenone (DMPA, purity 99\%) were purchased from Sigma-Aldrich. Three types of nonreactive polyhedral oligomeric silsesquioxanes: octakis[(glycidyloxypropyl) dimethylosiloxy)]octasilsesquioxane (G-POSS), octakis [(octafluorpentyloxypropyl)dimethylosiloxy)]octasilsesqui oxane (F-POSS) and octakis[(hydroxypropyl)dimethylosiloxy)]octasilsesquioxane (OH-POSS) were kindly donated by Wielkopolska Centre of Advanced Technologies (synthesized according to procedures described previously $[12,13])$. The substituents in the investigated compounds are linked to the POSS cage via $-\mathrm{Si}\left(\mathrm{CH}_{3}\right)_{2} \mathrm{O}-$ bridges; therefore, these compounds are classified as spherosilicates. All the chemicals were used as received. The structures and abbreviations of POSS compounds are shown in Fig. 1.

\section{Characterization and measurements}

\section{Viscosity}

The viscosity $(\eta)$ of the investigated systems was measured at $20{ }^{\circ} \mathrm{C}$ in the shear rate range $75-1500 \mathrm{~s}^{-1}$ with DVII + PRO Brookfield Digital Viscometer (cone-and-plate geometry) connected to the Ecoline Staredition 003 thermostat (Lauda). The viscosity was found to be independent on the shear rate. Additionally, for the system containing G-POSS, viscosity was measured at $40{ }^{\circ} \mathrm{C}$ (the temperature, at which the polymerization rate coefficients were estimated). The calculated viscosities ( $\left.\eta_{\text {calc }}\right)$ of the POSS/ HEMA mixtures were determined from the KendallMunroe equation (Eq. (1)) [14, 15]:

$\ln \eta_{\text {calc }}=\sum_{i=1}^{n} x_{\mathrm{i}} \cdot \ln \eta_{\mathrm{i}}$

where $x_{i}$ and $\eta_{i}$ are the molar fraction and viscosity of the $i$ component.

\section{FTIR study}

Intermolecular interactions between HEMA and POSS modifiers were examined by infrared spectroscopy. ATRFTIR spectra were recorded by the Nexus Nicolet model 5700 spectrometer (Thermo Fisher Scientific, USA) equipped with a $\mathrm{ZnSe}$ crystal ATR accessory.

\section{Photopolymerization kinetics}

Kinetic curves were obtained using DSC Pyris 6 (PerkinElmer, USA) equipped with a lid specially designed for photochemical measurements. The photocurable composition used for general kinetic studies contained $0,2,5,10$, 15 and 20 mass $\%$ of G-POSS, F-POSS or OH-POSS. The 2-mg samples were polymerized in open aluminum pans (diameter $6.6 \mathrm{~mm})$ under isothermal conditions $\left(20^{\circ} \mathrm{C}\right)$ in high-purity argon atmosphere $\left(<0.0005 \%\right.$ of $\left.\mathrm{O}_{2}\right)$. The 
<smiles>C[Si](C)(CCCO)O[Si]12O[Si]3(O[Si](C)(C)CCCO)O[Si]4(O[Si](C)(C)CCCO)O[Si](O[Si](C)(C)CCCO)(O1)O[Si]1(O[Si](C)(C)CCCO)O[Si](O[Si](C)(C)CCCO)(O2)O[Si](O[Si](C)(C)CCCO)(O3)O[Si](O[Si](C)(C)CCCO)(O4)O1</smiles>

OH-POSS<smiles>C[Si](C)(CCCOCC1CO1)O[Si]12O[Si]3(O[Si](C)(C)CCCOCC4CO4)O[Si]4(O[Si](C)(C)CCCOCC5CO5)O[Si](O[Si](C)(C)CCCOCC5CO5)(O1)O[Si]1(O[Si](C)(C)CCCOCC5CO5)O[Si](O[Si](C)(C)CCCOCC5CO5)(O2)O[Si](O[Si](C)(C)CCCOCC2CO2)(O3)O[Si](O[Si](C)(C)CCCOCC2CO2)(O4)O1</smiles>

G-POSS

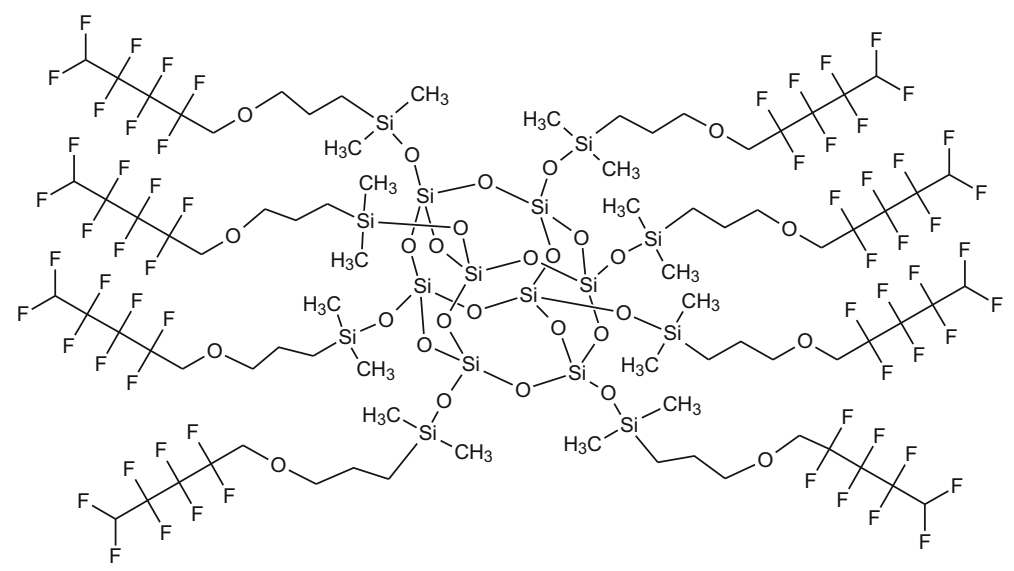

F-POSS

Fig. 1 Structures of POSS compounds used in the work

polymerization was initiated by LED lamp (LC-L1, Hamamatsu, $\lambda=365 \mathrm{~nm}, I_{0}=2.75 \mathrm{~mW} \mathrm{~cm}^{-2}$ ) in the presence of DMPA (1 mass\%).

All experiments were performed at least in triplicate. The reproducibility of the kinetic results was about $\pm 3 \%$. In the calculations, the heat of polymerization of the methacrylate group was assumed to be $56 \mathrm{~kJ} \mathrm{~mol}^{-1}$ for one double bond [16].

Detailed kinetic studies were carried out for HEMA/GPOSS system at $40{ }^{\circ} \mathrm{C}$, with light intensity $1 \mathrm{~mW} \mathrm{~cm}^{-2}$, DMPA concentration 0.2 mass $\%$ and G-POSS content: 0 , $2,5,10,15,20,25,30$ and 50 mass $\%$. Determination of propagation $\left(k_{\mathrm{p}}\right)$ and bimolecular termination $\left(k_{\mathrm{t}}^{\mathrm{b}}\right)$ rate coefficients was carried out for compositions containing 10 and 20 mass $\%$ of G-POSS. The rate coefficients were calculated from the experimental data obtained from postpolymerization processes, which were registered after stopping the irradiation at various degrees of double bond conversion. The calculations were performed over the first $10 \mathrm{~s}$ of the dark reaction using the bimolecular termination model [9] (Eqs. 2 and 3):

$\begin{aligned} \frac{[M]_{\mathrm{t}}}{\left(R_{\mathrm{p}}\right)_{\mathrm{t}}} & =\frac{2 \cdot k_{\mathrm{t}}^{\mathrm{b}}}{k_{\mathrm{p}}} \cdot t+\frac{[M]_{0}}{\left(R_{\mathrm{p}}\right)_{0}} \\ \left(R_{\mathrm{p}}\right)_{0} & =\frac{k_{\mathrm{p}}}{\left(k_{\mathrm{t}}^{\mathrm{b}}\right)^{0.5}} \cdot[M]_{0} \cdot\left(\phi \cdot I_{\mathrm{a}}\right)^{0.5}\end{aligned}$

where $\left(R_{\mathrm{p}}\right)_{\mathrm{t}}$ and $\left(R_{\mathrm{p}}\right)_{0}$ are the polymerization rates at time $t$ of the dark reaction and at the moment of breaking the irradiation, respectively, $[M]_{\mathrm{t}}$ and $[M]_{0}$ are concentrations of double bond at time $t$ of the dark reaction and at the moment of breaking the irradiation, respectively, $\phi$ denotes quantum yield of initiation and $I_{\mathrm{a}}$ is intensity of the light absorbed. The rate coefficients were calculated in the form of $k_{\mathrm{p}} \cdot F$ and $k_{\mathrm{t}}^{\mathrm{b}} \cdot F$, where $F=\phi \cdot I_{\mathrm{a}}$; it was assumed that $F$ is constant in the range of the conversions studied. 


\section{Characterization of composites}

Samples for characterization of thermal and mechanical properties have been polymerized in a two-part stainless steel mold covered with a poly(ethylene terephthalate) foil and placed in a Dymax UV 5000 Flood lamp (metal halide bulb, 300-670 nm; light intensity $310 \mathrm{~mW} \mathrm{~cm}^{-2}$ measured with Dymax radiometer ACCU-CAL-50).

\section{Thermal properties}

Thermal properties of the samples were studied by DSC and thermogravimetry (TG).

Glass transition temperatures $T_{\mathrm{g}}$ were determined using the DSC1 (Mettler Toledo, Switzerland) instrument under nitrogen atmosphere at the heating rate of $20{ }^{\circ} \mathrm{C} \mathrm{min}^{-1}$ in the temperature range from $-80^{\circ} \mathrm{C}$ to $180{ }^{\circ} \mathrm{C}$. $T_{\mathrm{g}}$ was evaluated from the second run of the DSC measurement and was taken as an average value from three measurements. The reproducibility of the determination was about $1{ }^{\circ} \mathrm{C}$.

Thermogravimetric analysis (TGA) (the thermal resistance) of the obtained materials was carried out using TG 209 F3 Tarsus thermogravimetric analyzer (NETZSCHGeratebau $\mathrm{GmbH}$, Germany). 10-mg samples were heated in $\mathrm{Al}_{2} \mathrm{O}_{3}$ crucibles from 40 to $800{ }^{\circ} \mathrm{C}$ at a heating rate of $10{ }^{\circ} \mathrm{C} \min ^{-1}$ under nitrogen atmosphere $\left(\mathrm{N}_{2}\right.$ protection gas

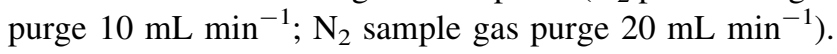

\section{Mechanical properties}

The tensile properties were measured with Zwick/Roell universal testing machine model Z020 (Zwick GmbH \& Co. KG, Germany) according to PN-EN ISO 527-1:1998 (crosshead speed of $5 \mathrm{~mm} \mathrm{~min}^{-1}$ ). The Shore D hardness on Zwick Roell apparatus was measured according to DIN 53505 . The results were obtained as the average values of six measurements for tensile properties or ten measurements for hardness.

\section{Results and discussion}

\section{Miscibility of POSS with HEMA and poly-HEMA}

Prior to polymerization, the components of the formulations (HEMA and POSS) showed very good miscibility (transparent solutions). However, during the polymerization, phase separation (turbidity of the sample) appeared in all the systems under investigation. A slight separation was observed even after addition of only 2 mass $\%$ of the POSS modifiers; it was most noticeable in the case of F-POSS, and somewhat weaker and similar for G-POSS and $\mathrm{OH}-$
POSS. The visible phase separation indicates that the produced poly-HEMA/POSS are two-phase materials which can be considered as a type of (micro)composites.

\section{Intermolecular interactions in HEMA/POSS systems}

Intermolecular interactions occur mainly between $\mathrm{OH}$ or $\mathrm{C}=\mathrm{O}$ groups from HEMA and $\mathrm{OH}$ or ether groups from the modifiers. These functional groups can contribute to $\mathrm{OH} \cdots \mathrm{OH}, \mathrm{OH} \cdots \mathrm{O}=\mathrm{C}$ and $\mathrm{OH} \cdots \mathrm{O}$ types of inter- and intramolecular $\mathrm{H}$ bonds. FTIR spectra of the investigated HEMA/POSS systems in the range of $\mathrm{OH}$ and $\mathrm{C}=\mathrm{O}$ group absorption are shown in Fig. 2.

The absorption of HEMA in the $\mathrm{O}-\mathrm{H}$ stretching region (about $3150-3670 \mathrm{~cm}^{-1}$ ) consists of several overlapping bands which can be ascribed to $\mathrm{OH} \cdots \mathrm{OH}$ type of $\mathrm{H}$ bonds (the band component at $3330-3350 \mathrm{~cm}^{-1}$ ), an overtone of $\mathrm{C}=\mathrm{O}$ stretching (at $3427 \mathrm{~cm}^{-1}$ ), $\mathrm{OH} \cdots \mathrm{C}=\mathrm{O}$ type of $\mathrm{H}$ bonds (with the maximum at about $3520 \mathrm{~cm}^{-1}$ ) and free hydroxyl groups (the band at $3620-3670 \mathrm{~cm}^{-1}$ ) [17]. Interactions of $\mathrm{OH} \cdots \mathrm{C}=\mathrm{O}$ type are reflected also in the $\mathrm{C}=\mathrm{O}$ stretching region (free $\mathrm{C}=\mathrm{O}$ groups at $\sim 1718 \mathrm{~cm}^{-1}$ and $\mathrm{C}=\mathrm{O}$ involved in $\mathrm{C}=\mathrm{O} \cdots \mathrm{H}-\mathrm{O}$ bonding at $1701 \mathrm{~cm}^{-1}$ ) [17]. OHPOSS contains eight hydroxyl groups which form strong hydrogen bonds between its molecules (the band with the absorption maximum at about $3333 \mathrm{~cm}^{-1}$ ) [18].

Addition of OH-POSS to HEMA causes some changes in the shape of the $\mathrm{OH}$ absorption band. With the increase in the amount of modifier, the absorption of $\mathrm{OH}$ groups involved in the $\mathrm{OH} \cdots \mathrm{C}=\mathrm{O}$ interactions disappears gradually, while the absorption of the band associated with $\mathrm{OH} \cdots \mathrm{OH}$ interactions increases. A similar but much less pronounced effect is observed in the case of G-POSS which may be related to the formation of $\mathrm{OH} \cdots \mathrm{O}$ bonds. (Observation of the oxirane group absorption was not possible due to the overlapping of corresponding bands in the range of $750-950 \mathrm{~cm}^{-1}$ with $\mathrm{Si}-\mathrm{CH}_{3}$ absorption band.) F-POSS does not appear to affect the absorption of the $\mathrm{OH}$ band of HEMA.

The disappearance of $\mathrm{OH} \cdots \mathrm{C}=\mathrm{O}$ interactions in HEMA is confirmed by changes in the $\mathrm{C}=\mathrm{O}$ stretching region. In the presence of OH-POSS, the intensity of the band at $\sim 1718 \mathrm{~cm}^{-1}$ increases at the expense of the intensity of the band at $1701 \mathrm{~cm}^{-1}$ indicating disruption of $\mathrm{OH} \cdots \mathrm{C}=\mathrm{O}$ bonding and establishing of other interactions, e.g., $\mathrm{OH} \cdots \mathrm{OH}$. A similar effect in the case of G-POSS is much less pronounced. On the other hand, the addition of F-POSS to HEMA increases the absorption intensity of the $\mathrm{H}$-bonded $\mathrm{C}=\mathrm{O}$ group suggesting rather weak interactions between HEMA and F-POSS and enhancing inter- or intramolecular interactions between the monomer molecules. Observation of the behavior of the $\mathrm{Si}-\mathrm{O}-\mathrm{Si}(1040 \div$ 
(a)

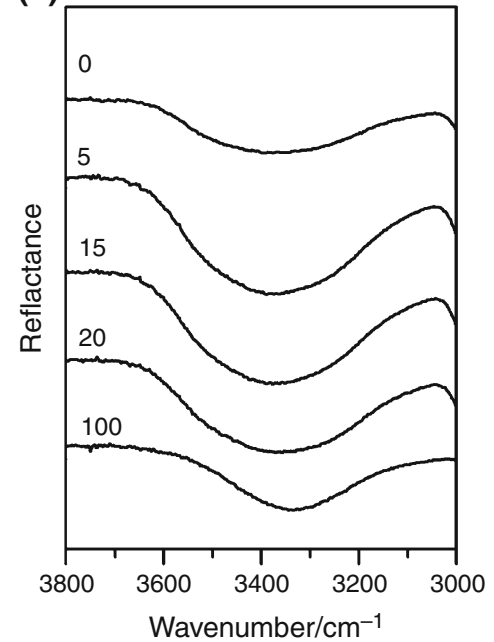

(b)

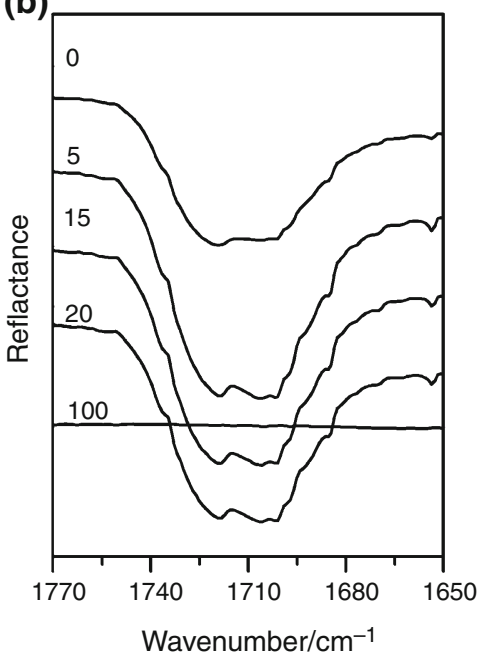

(c)

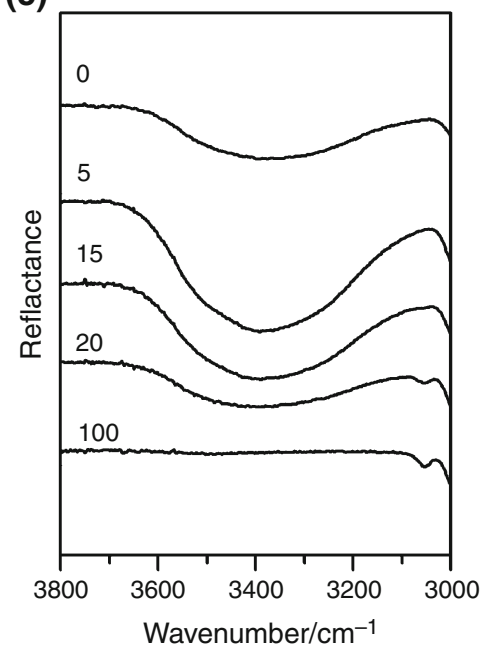

(d)

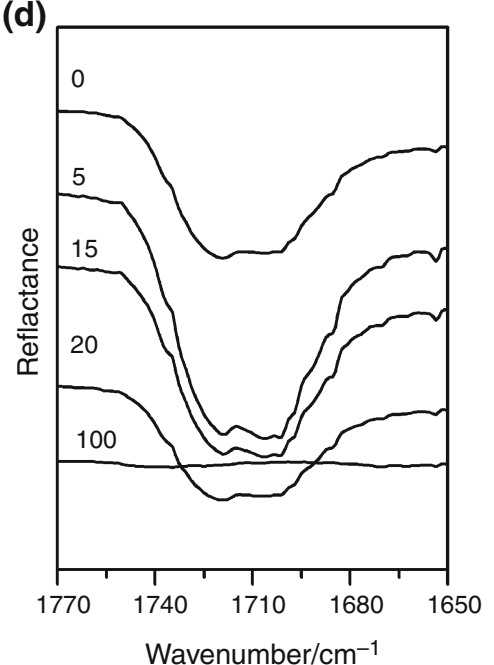

(e)

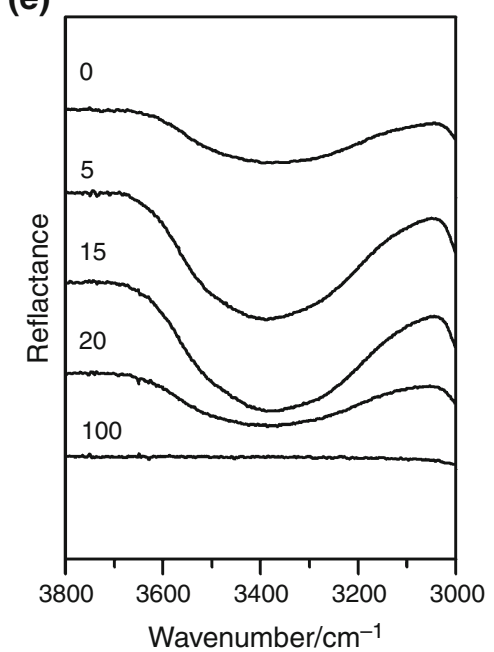

(f)

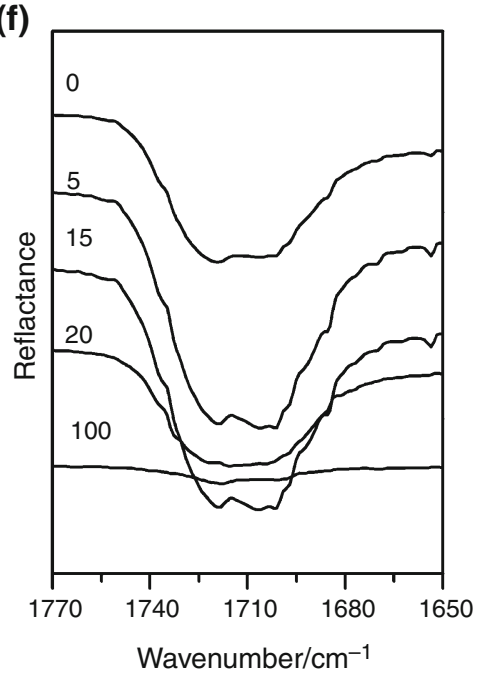

Fig. 2 FTIR spectra of neat HEMA and its mixtures with a, b OH-POSS, $\mathbf{c}, \mathbf{d}$ G-POSS and e, f F-POSS in the a, c, e OH absorption region and b, d, $\mathbf{f} \mathrm{C}=\mathrm{O}$ absorption region. The numbers indicate the POSS content (mass\%) in the composition

$\left.1125 \mathrm{~cm}^{-1}\right), \mathrm{C}-\mathrm{O}-\mathrm{C}\left(1045 \div 1155 \mathrm{~cm}^{-1}\right)$ or $-\mathrm{CF}_{2}-(1135$ $\div 1240 \mathrm{~cm}^{-1}$ ) absorption bands [19] was not possible due to their overlapping.

In general, FTIR spectra seem to confirm the existence of interactions between the monomer and OH-POSS or G-POSS. However, these interactions are not sufficient to maintain full compatibility between the polymer and the modifiers.

\section{Viscosity of HEMA/POSS compositions}

Viscosity is one of parameters in which knowledge is necessary to design technological curing conditions and one of the most important factors affecting the polymerization kinetics. Termination is a diffusion-controlled process; therefore, the termination rate coefficient $k_{\mathrm{t}}^{\mathrm{b}}$ is inversely proportional to the viscosity $\left(k_{\mathrm{t}}^{\mathrm{b}} \sim \eta^{-1}\right)$, whereas the polymerization rate $R_{\mathrm{p}}$ is related to the termination rate coefficient as $R_{\mathrm{p}} \sim\left(k_{\mathrm{t}}^{\mathrm{b}}\right)^{-0.5}$ [20,21]. Changes in the viscosity of a composition may also indicate changes in the interactions between the components. The viscosity of the compounds studied in this work differs significantly at $20{ }^{\circ} \mathrm{C}$ : from $6.79 \mathrm{mPa} \mathrm{s}$ for HEMA and $395 \mathrm{mPa} \mathrm{s}$ for G-POSS up to $1877 \mathrm{mPa}$ s for F-POSS. At $20^{\circ} \mathrm{C}$, OHPOSS is solid. Thus, changes in HEMA/POSS ratio must strongly affect the viscosity of their mixture.

Experimental viscosity values at $20{ }^{\circ} \mathrm{C}$ and viscosities calculated from Eq. (1) (developed for mixtures of liquids with similar intermolecular interactions and molar volumes) are presented in Fig. 3a. The increase in the formulation viscosity is the strongest in the case of OH-POSS which to a large extent can be attributed to strong HEMA/ POSS interactions confirmed by FTIR. The influence of F-POSS and G-POSS is much smaller and similar. 
(a)

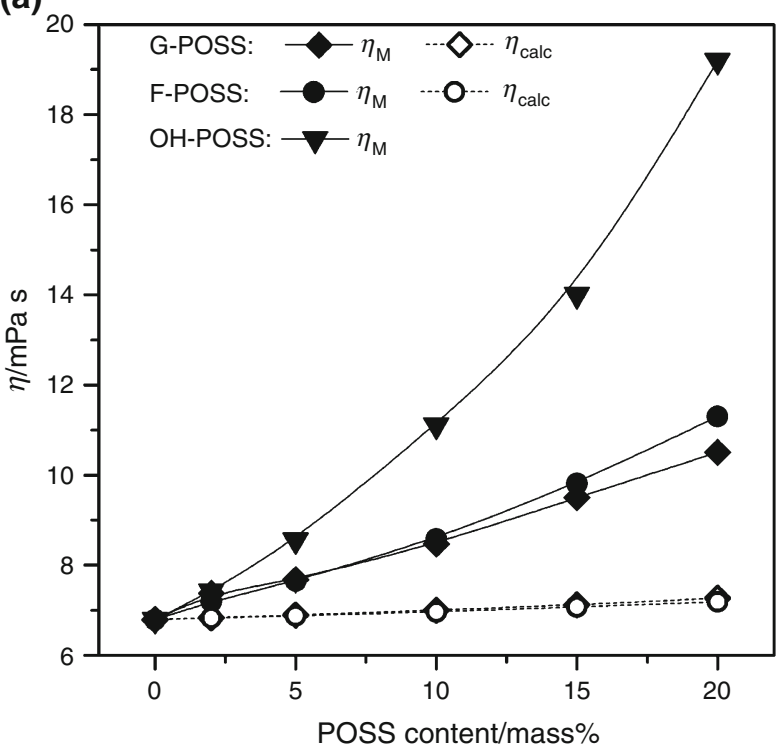

(b)

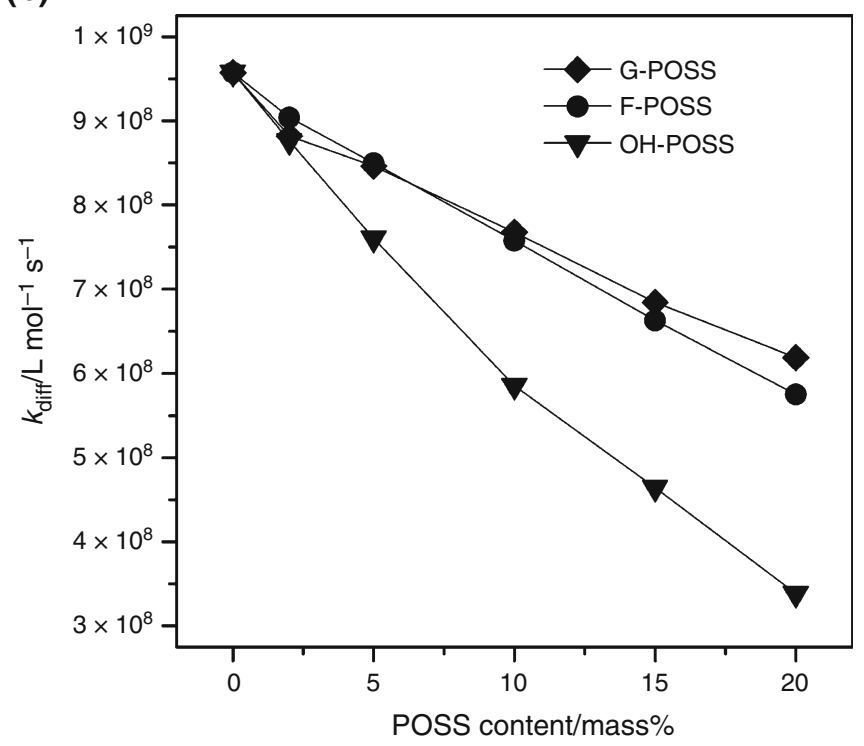

Fig. 3 Measured ( $\eta_{\mathrm{M}}$, solid symbols) and calculated ( $\eta_{\text {calc }}$, open symbols) viscosities (a) and diffusion rate coefficient $k_{\text {diff }}(\mathbf{b})$ of HEMA/POSS compositions at $20^{\circ} \mathrm{C}$ as a function of POSS content. The lines are guides to the eye

Calculation of theoretical values of viscosity was possible only for compositions containing G-POSS and F-POSS. Experimental values show significant deviations from the theoretical values, suggesting the occurrence of viscosity synergism (slightly stronger for F-POSS), which in turn may indicate strong interactions. In general, the occurrence of synergism indicates that the viscosity of the monomer/modifier associates is greater than the viscosity of the associates in the pure compounds. Alternatively, one can consider an increase in friction forces in the monomer/ POSS associates as a result of physical interactions, e.g., entanglements. However, the molar volumes of the components (HEMA and POSS) differ significantly which can enhance the observed deviations; despite this, we cannot exclude the influence of intermolecular interactions. A similar synergism of viscosity we also observed in the case of HEMA/M-POSS compositions [9]. The occurrence of this phenomenon is very important for the design of technological parameters of curing (e.g., photocurable lacquers or varnishes), because the viscosity of the formulation can be significantly higher than expected.

Viscosity affects the propagation/termination steps if the diffusion coefficient, $k_{\text {diff }}$, is lower than the corresponding rate coefficients. The calculated $k_{\text {diff }}$ values (Fig. $3 \mathrm{~b}$ ) show that at the beginning of the polymerization, both propagation and termination rates will not depend on translational diffusion. (The propagation and bimolecular termination rate coefficients for methacrylates are on the order of $10^{3}$ and $10^{7} \mathrm{M}^{-1} \mathrm{~s}^{-1}$, respectively [16].)

\section{Photopolymerization of HEMA/POSS systems}

\section{General kinetics}

Kinetics of HEMA photopolymerization in the presence of POSS derivatives can be affected by the following factors: (1) change in the initial viscosity of the formulation, (2) dilution of the monomer, (3) system compatibility and (4) the impact of the inorganic POSS cage. Polymerization traces (at $20^{\circ} \mathrm{C}$ ) of formulations containing various amounts of the modifiers are shown in Fig. 4. Figure $4 \mathrm{a}-\mathrm{c}$ presents the dependence of the polymerization rate $R_{\mathrm{p}}$ on irradiation time $t$, and Fig. $4 \mathrm{~d}-\mathrm{f}$ shows the polymerization rate $R_{\mathrm{p}}$ as a function of conversion of double bonds $p$.

HEMA polymerizes with the formation of a linear polymer, and its polymerization kinetic curve is typical for a monomethacrylate polymerization with the steady state and gel effect regions. The development of the gel effect becomes clearly visible at about $15-20 \%$ of the double bond conversion. The most characteristic point is the maximum polymerization rate, $R_{\mathrm{p}}^{\max }$ (the end of the gel effect). During the polymerization of neat HEMA, this point is reached at around $p=40 \%$ ( $p$ at $R_{\mathrm{p}}^{\max }$ is defined as $\left.p^{\mathrm{Rm}}\right)$. When the deceleration begins, $R_{\mathrm{p}}$ decreases sharply until polymerization ceases.

The addition of nonreactive POSS derivatives strongly affects the kinetics of HEMA polymerization, and the qualitative effect of all three compounds is similar (Figs. 4, 5): (1) addition of increasing amounts of POSS to HEMA leads to a gradual disappearance of steady state, which also results in shortening the time $\left(t^{\mathrm{Rm}}\right)$ after which the 

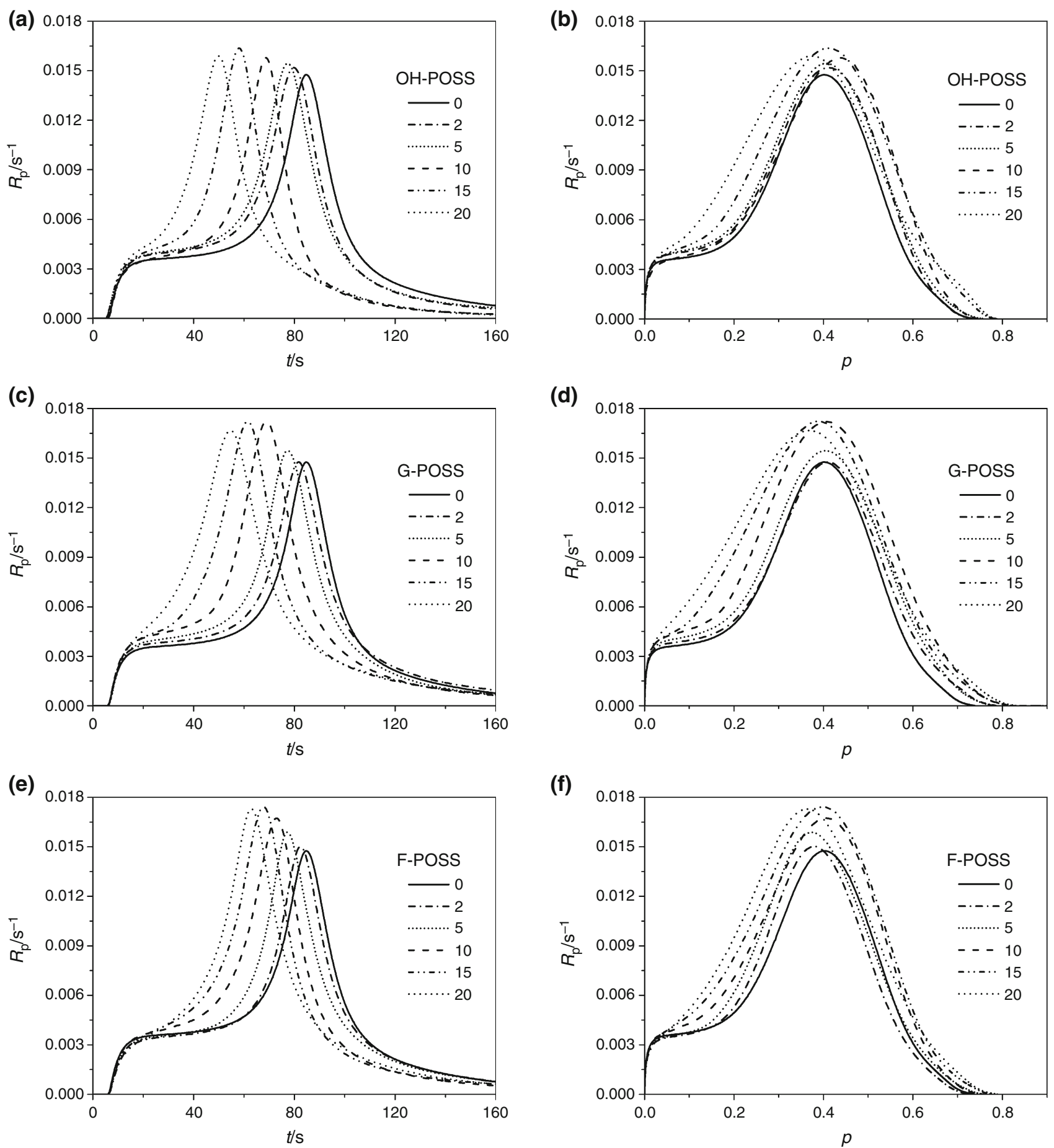

Fig. 4 Polymerization rate of HEMA in the presence of a, d OHPOSS, $\mathbf{b}, \mathbf{e}$ G-POSS and $\mathbf{c}, \mathbf{f}$ F-POSS as a function of irradiation time $t$ and double bond conversion $p . T=20^{\circ} \mathrm{C}, I_{0}=1 \mathrm{~mW} \mathrm{~cm}^{-2}$, DMPA

maximum polymerization rate, $R_{\mathrm{p}}^{\max }$, is reached, (2) $R_{\mathrm{p}}^{\max }$ increases with the amount of POSS added, but only to its certain concentration (corresponding to the most reactive composition characterized by the highest $R_{\mathrm{p}}^{\max }$ value); above this content, $R_{\mathrm{p}}^{\max }$ begins to decrease, (3) the final degree of double bond conversion, $p^{\mathrm{f}}$, increases slightly as

conc. 0.2 mass \%. The numbers indicate the POSS content (mass\%) in the composition

the concentration of modifiers increases, (4) $p^{\mathrm{Rm}}$ values appear to be independent of the POSS concentration to about 15 mass $\%$.

As mentioned above, $k_{\mathrm{t}}^{\mathrm{b}}$ is inversely proportional to the viscosity of the system: $k_{\mathrm{t}}^{\mathrm{b}} \sim \eta^{-1}$; thus, a significant increase in the initial viscosity of the POSS-containing 

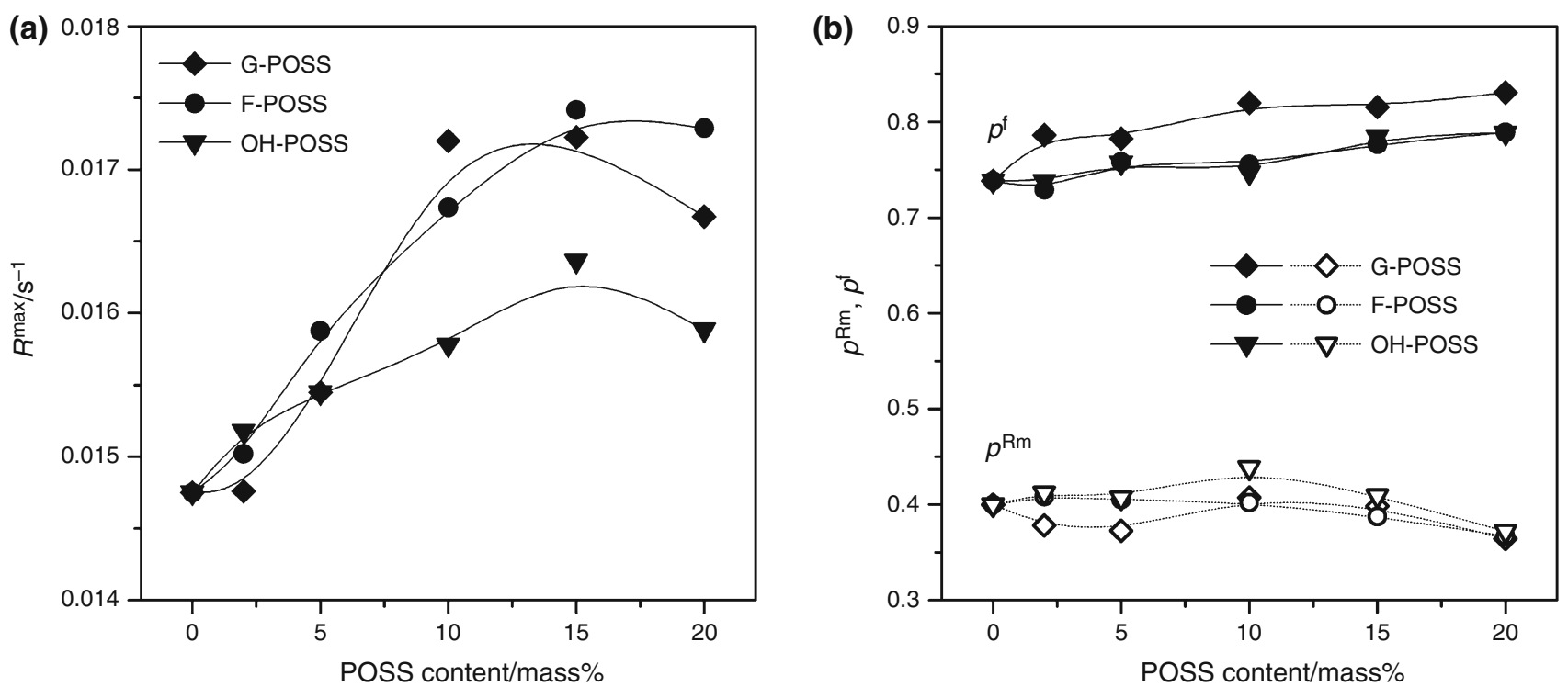

Fig. 5 Dependence of $R_{\mathrm{p}}^{\max }(\mathbf{a})$ and $p^{\mathrm{f}}$ and $p^{\mathrm{Rm}}(\mathbf{b})$ values on POSS content at $20{ }^{\circ} \mathrm{C}$. The lines are guides to the eye

formulations should result in faster polymerization. Therefore, the most important reason for accelerating HEMA polymerization after the addition of the tested POSS derivatives may be the increase in the initial viscosity of the formulation. Increase in viscosity leads to suppression of termination (decrease in $k_{\mathrm{t}}^{\mathrm{b}}$ ) due to the slowing down of macroradical diffusion, which in turn enhances the gel effect. From among three types of diffusion processes controlling the termination: segmental diffusion at low conversions, translational diffusion after the beginning of the gel effect and reaction diffusion after reaching conversions in the range of $p^{\mathrm{Rm}}$ [9], only translational diffusion, the dominance of which determines the occurrence of the gel effect, depends on the length of the polymer chain and the viscosity of the system (both initial and increasing during the polymerization). Therefore, the higher the initial viscosity, the earlier the gel effect occurs. This is observed in our systems. Enhancement of the gel effect also leads to an increase in $R_{\mathrm{p}}^{\max }$ values.

However, the conversion at which $R_{\mathrm{p}}^{\max }$ appears $\left(p^{\mathrm{Rm}}\right.$ corresponds to the reaction point, when the reaction diffusion begins to dominate in the termination mechanism) practically does not depend on the POSS content (up to $\sim 15$ mass $\%$ ). When discussing this behavior, we should take into account the competition between two effects: (1) increase in the initial viscosity due to the addition of highly viscous POSS, which also increases the viscosity of the polymerizing system (compared to the modifier-free system) already at lower conversions, and (2) dilution of the system by an unreactive modifier which inhibits the increase in viscosity due to polymer formation, especially at higher conversions. In other words, the viscosity of the polymerizing system increases more slowly in the presence of POSS derivatives, and the higher the POSS concentration, the stronger the effect. The practical insensitivity of $p^{\mathrm{Rm}}$ values to POSS content can be associated with the influence of these two opposed effects.

The increase in the gel effect, as the concentration of POSS increases, is completed when the content of POSS reaches 15 mass\%. A further increase in POSS concentration causes a reduction in $p^{\mathrm{Rm}}$, which indicates that the reaction diffusion becomes the dominant termination mechanism with ever lower conversions. $R_{\mathrm{p}}^{\max }$ decreases compared to formulation containing 15 mass $\%$ of the additive because the gel effect cannot be fully developed due possibly to too high dilution of the system. Increasing the concentration of modifiers causes a small but continuous increase in the $p^{\mathrm{f}}$ values. This is related to the plasticization of the polymer by additives, because the final conversion depends on the mobility of the polymerizing system.

Although the general explanation of the effect of all nonreactive POSS investigated on the HEMA polymerization kinetics is the same, there are some differences in the effects of the individual compounds. This may be related, at least in part, to the complicating phase separation effect that occurs during the polymerization. At the early stages of the reaction, the polymerizing system is a solution of the modifier and the polymer in the monomer. Upon reaching certain conversion (certain polymer concentration), the miscibility of the system becomes too small to keep the modifier completely dissolved and it begins to separate, changing the viscosity of the phase in which the polymerization takes place. So, further polymerization occurs in the monomer/polymer/POSS phase depleted with the modifier. Such a decrease in modifier concentration in 
the polymerizing phase and the resulting change in viscosity can affect the polymerization kinetics. The phase separation can also weaken the plasticizing effect of the additive, which in turn can affect the final conversion. Therefore, it is difficult to determine unambiguously what is the reason for the lower $R_{\mathrm{p}}^{\max }$ values of the system containing OH-POSS. It can be speculated, for example, that due to the best compatibility of the poly-HEMA/OHPOSS system, the amount of POSS separating during the reaction is the smallest and the dilution effect is the strongest. It is also possible, however, that the much higher initial viscosities of the HEMA/OH-POSS formulations result in an earlier completion of the gel effect, resulting in lower $R_{\mathrm{p}}^{\max }$ values.

\section{Detailed kinetics}

To obtain more information on the effect of nonreactive POSS derivatives on HEMA polymerization, we have performed detailed kinetic studies for the selected system, including the determination of the polymerization rate coefficients. Because the effect of all three POSS compounds is similar, we chose G-POSS as a model modifier and followed reaction kinetics over a wider range of its concentration (up to 50 mass $\%$ ). The rate coefficients were determined for compositions containing 10 and 20 mass $\%$ of the modifier.

The investigations presented in this section were carried out at $40{ }^{\circ} \mathrm{C}$, at lower light intensity and lower photoinitiator concentration. The change in the polymerization conditions was dictated by the need to slow down the reaction in order to increase the accuracy of determining the rate coefficients. (It should be remembered that HEMA photopolymerization rate decreases with increasing temperature [22].)

The viscosity of the formulation as a function of G-POSS content, measured at $40{ }^{\circ} \mathrm{C}$, is shown in Fig. 6. At this temperature, HEMA viscosity is $3.4 \mathrm{mPa} \mathrm{s}$, whereas viscosity of G-POSS is $128.2 \mathrm{mPa} \mathrm{s}$. Obviously, these viscosities are lower than at $20^{\circ} \mathrm{C}$, but measurements in the range of $0-100 \%$ of G-POSS concentration well illustrate synergism of viscosity. The greatest difference between the experimental and calculated viscosity occurs at 80 mass \% (21.2 mol\%) of the modifier which indicates that intermolecular interactions between HEMA and G-POSS are the strongest when HEMA to G-POSS mol. ratio is $4: 1$.

Changes in polymerization conditions led to the expected decrease in the polymerization rate (about two times) (Fig. 7). The general picture of the dependence of polymerization parameters on the G-POSS content is analogous to $20^{\circ} \mathrm{C}$. However, the maximum on the curve $R_{\mathrm{p}}^{\max }=f($ POSS content $)$ has shifted from around

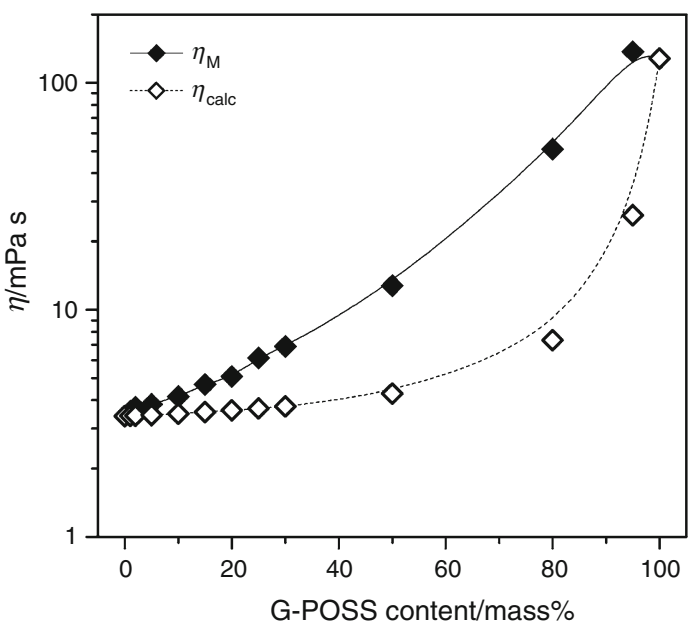

Fig. 6 Measured ( $\eta_{\mathrm{M}}$, solid symbols) and calculated ( $\eta_{\text {calc }}$, open symbols) viscosities of HEMA/G-POSS compositions at $40{ }^{\circ} \mathrm{C}$ as a function of G-POSS content. The lines are guides to the eye

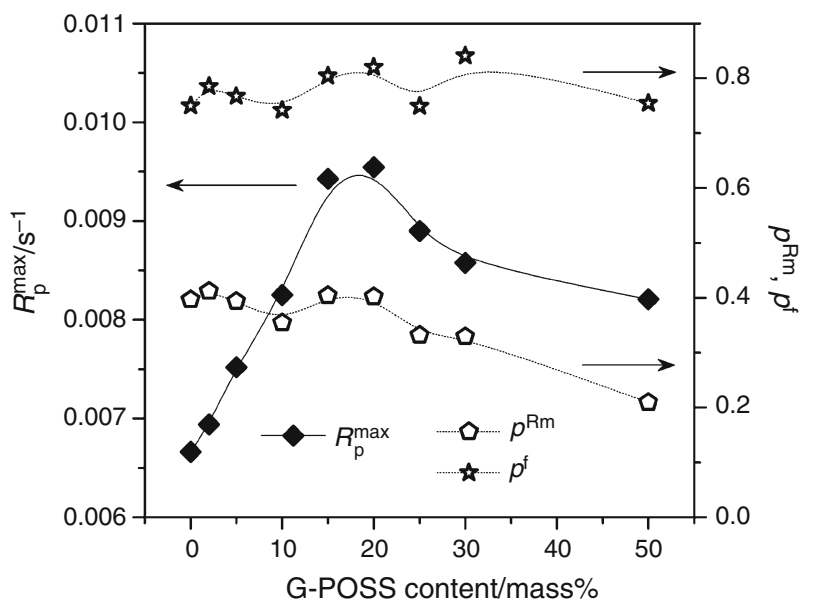

Fig. 7 Dependence of $R_{\mathrm{p}}^{\max }, p^{\mathrm{f}}$ and $p^{\mathrm{Rm}}$ on G-POSS content at $40^{\circ} \mathrm{C}$. The lines are guides to the eye

$10 \div 15$ mass $\%$ to 20 mass $\%$, which is mainly related to the increased polymerization temperature and the resulting decrease in viscosity. Thus, to achieve an analogous effect of slowdown the termination (necessary to obtain a composition with the highest $R_{\mathrm{p}}^{\max }$ ), the content of the more viscous compound (G-POSS) must be increased. However, the viscosity of the most reactive composition at $20{ }^{\circ} \mathrm{C}$ is about $8 \div 9 \mathrm{mPa} \mathrm{s}$ (at $10 \div 15$ mass\% of G-POSS), whereas at $40{ }^{\circ} \mathrm{C}$, it is only about $5 \mathrm{mPa}$ s $(20$ mass $\%$ of POSS). This proves that the influence of $8 \mathrm{G}-\mathrm{POSS}$ on the HEMA polymerization is not only due to the reduction in the $k_{\mathrm{t}}^{\mathrm{b}}$ coefficient.

Determination of polymerization rate coefficients as functions of conversion degree $p$ was performed for systems containing 0,10 and 20 mass $\%$ of G-POSS. (The corresponding kinetic curves are shown in Fig. 8.) The latter composition is characterized by the highest $R_{\mathrm{p}}^{\max }$ 

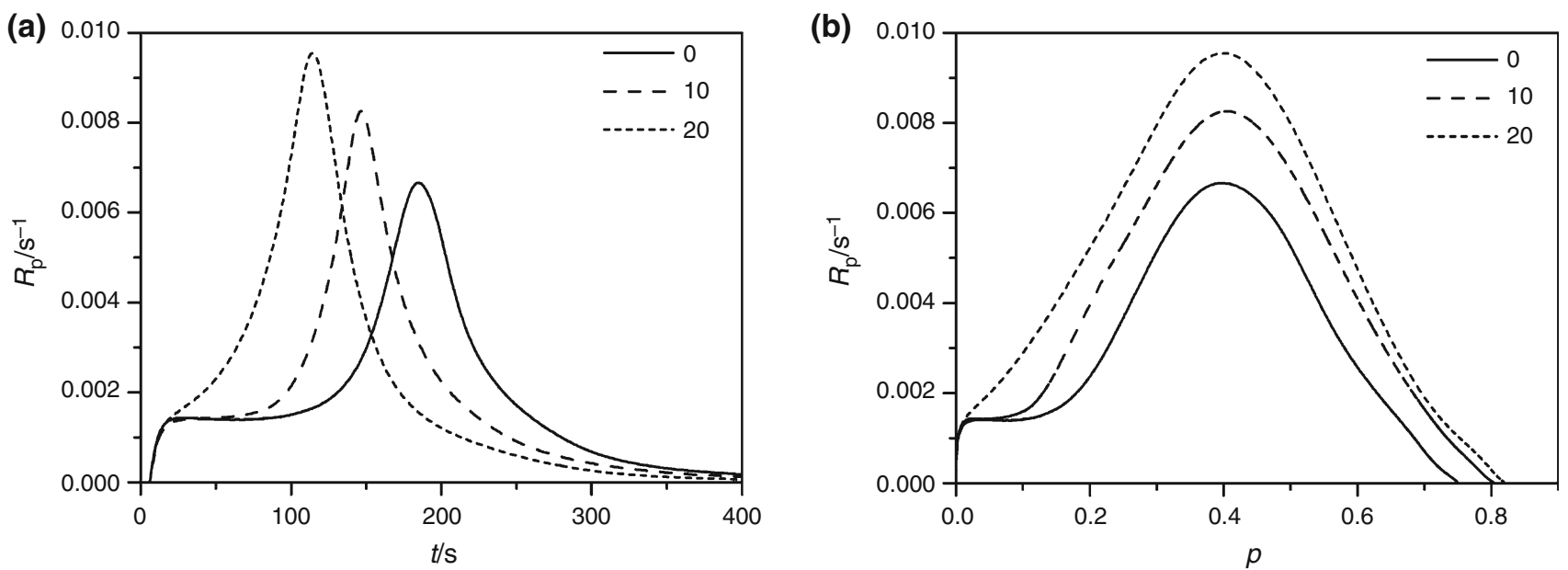

Fig. 8 Polymerization rate of HEMA/G-POSS systems as a function of irradiation time $t$ (a) and degree of double bond conversion $p$ (b). $T=40{ }^{\circ} \mathrm{C}, I_{0}=1 \mathrm{~mW} \mathrm{~cm}{ }^{-2}$, DMPA conc. 0.2 mass $\%$. The numbers indicate G-POSS content (mass $\%$ ) in the composition

value among compositions from the entire range of G-POSS content tested; thus, the differences between the rate coefficients of formulation with and without the modifier should be greatest. Measurements were carried out in the conversion range up to 40 mass $\%\left(\leq p^{\mathrm{Rm}}\right)$ due to too large deviations of the polymerization conditions after the completion of the gel effect from those described by the assumed kinetic model.

Parameters related to rate coefficients of propagation $\left(k_{\mathrm{p}} \cdot F\right)$ and termination $\left(k_{\mathrm{t}}^{\mathrm{b}} \cdot F\right)$ and their ratio as functions of double bond conversion $p$ are shown in Fig. 9. Although these parameters do not represent real values of rate coefficients, their determination provides information on

(a)

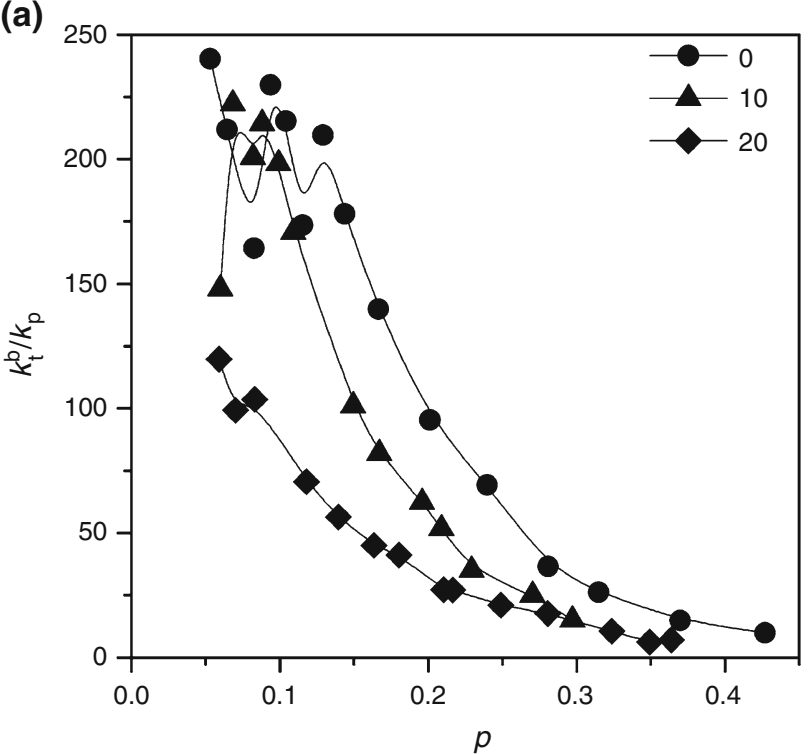

changes in actual $k_{\mathrm{p}}$ and $k_{\mathrm{t}}^{\mathrm{b}}$ coefficients in the presence of modifiers.

The dependence of the $k_{\mathrm{t}}^{\mathrm{b}} / k_{\mathrm{p}}$ ratio on the conversion is shown in Fig. 9a. Despite some scatter of data from the early stages of the reaction, a very slight decrease in this ratio with increasing conversion in the steady state region can be observed for the neat monomer and composition containing 10 mass $\%$ of the modifier. This stage is not observed for composition modified with $20 \%$ of G-POSS due to the lack of the steady state (compare Fig. 8). After beginning of the gel effect, a rapid drop of the $k_{\mathrm{t}}^{\mathrm{b}} / k_{\mathrm{p}}$ ratio occurs; this drop is slowed down at about $35 \%$ of double bond conversion, with the tendency to form a plateau, characteristic of the reaction stage, when termination

(b)

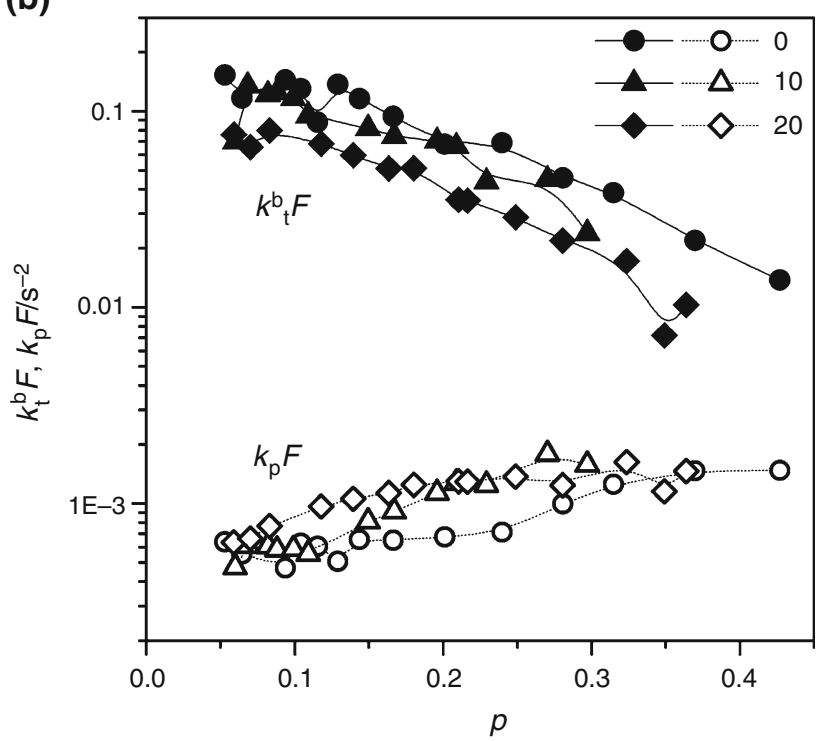

Fig. 9 The ratio of the photopolymerization rate coefficients $k_{\mathrm{t}}^{\mathrm{b}} / k_{\mathrm{p}}(\mathbf{a})$ and the individual parameters $k_{\mathrm{p}} \cdot F$ and $k_{\mathrm{t}}^{\mathrm{b}} \cdot F(\mathbf{b})$ as functions of double bond conversion $p$ at $40{ }^{\circ} \mathrm{C}$. The numbers indicate G-POSS content (mass\%) in the composition. The lines are guides to the eye 
becomes controlled by the reaction diffusion (independent on the chain length). Such a dependence is typical for the behavior of $k_{\mathrm{t}}^{\mathrm{b}}$ with increasing conversion; reflection of $k_{\mathrm{t}}^{\mathrm{b}}$ changes on the $k_{\mathrm{t}}^{\mathrm{b}} / k_{\mathrm{p}}=f(p)$ dependence results from the fact that the termination rate coefficients are about $3 \div 4$ orders of magnitude higher than the propagation rate coefficients. The addition of G-POSS results in a marked decrease in the $k_{\mathrm{t}}^{\mathrm{b}} / k_{\mathrm{p}}$ ratio, mainly associated with the decrease in $k_{\mathrm{t}}^{\mathrm{b}}$, although some increase in the $k_{\mathrm{p}}$ value cannot be ruled out.

The individual parameters $k_{\mathrm{p}} \cdot F$ oraz $k_{\mathrm{t}}^{\mathrm{b}} \cdot F$ are shown in Fig. 9b. The behavior of $k_{\mathrm{t}}^{\mathrm{b}} \cdot F$ with the increasing conversion corresponds exactly to the behavior of the $k_{\mathrm{t}}^{\mathrm{b}} / k_{\mathrm{p}}$ ratio described above. Clearly visible is also the influence of G-POSS consisting of the reduction in the $k_{\mathrm{t}}^{\mathrm{b}} \cdot F$ values; this is mainly due to the increased initial viscosity of the composition. Interestingly, in the presence of G-POSS, the decrease in the $k_{\mathrm{t}}^{\mathrm{b}} \cdot F$ values with the increase in conversion is slower (lower slope of the curve, better seen in Fig. 9a). This can suggest that although the macroscopic increase in viscosity caused by the addition of G-POSS hinders the translational diffusion of macroradicals, it is likely that the presence of POSS cages mitigates these difficulties by exerting a slip effect.
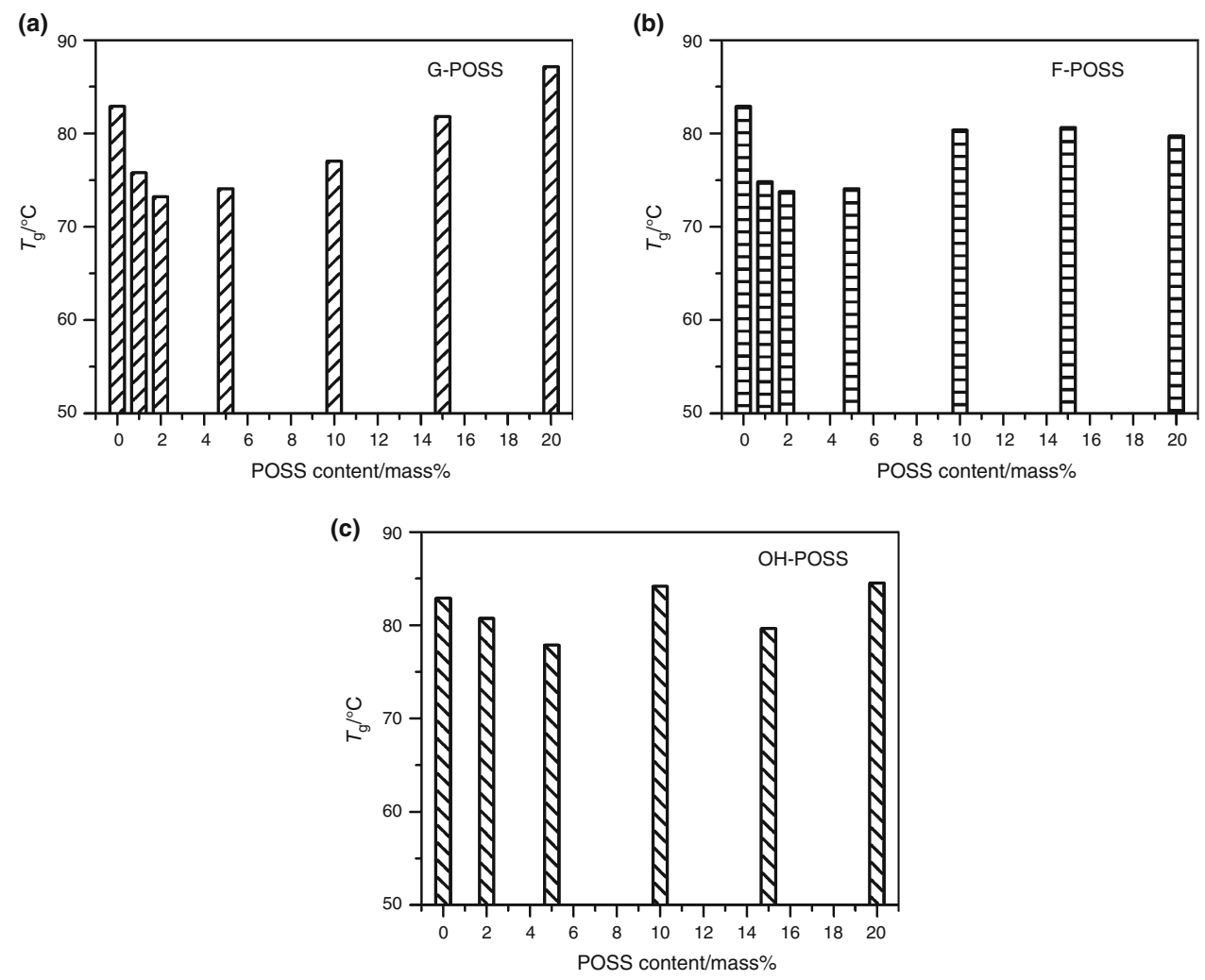

Fig. 10 The glass transition temperature $T_{\mathrm{g}}$ of poly-HEMA/G-POSS (a), poly-HEMA/F-POSS (b) and poly-HEMA/OH-POSS (c) materials as a function of POSS content 
POSS affects this value, which proves that the phase separation was incomplete and a part of the modifiers remained dissolved in the polymer. In our preliminary study [23], we indicated that addition of small amounts (up to about 5 mass\%) of POSS derivatives reduces $T_{\mathrm{g}}$ due to disruption of hydrogen bonding between poly-HEMA chains. This effect, and the effect of POSS cages increasing the free volume [23, 24], causes plasticization of the material. $T_{\mathrm{g}}$ begins to rise when POSS content in the composite exceeds 5 mass\%. Such behavior suggests that separated POSS domains behave like nanofiller aggregates, introducing topological constraints and steric hindrance, which leads to an increase in $T_{\mathrm{g}}$. Interestingly, the described effect is the lowest for OH-POSS which is probably due to the strong hydrogen bonds between $\mathrm{OH}$ groups in $\mathrm{OH}-\mathrm{POSS}$ and in poly-HEMA that reduce the mobility of polymer chains.
Table 1 The results of thermal decomposition of POSS compounds, polymer matrix and composites containing 20 mass \% of the modifiers

\begin{tabular}{lllll}
\hline & $T_{5} /{ }^{\circ} \mathrm{C}$ & $T_{50} /{ }^{\circ} \mathrm{C}$ & $R / \%$ & Theoretical contribution of POSS cages $/ \%$ \\
\hline OH-POSS & 237 & - & 62.2 & 28.2 \\
G-POSS & 350 & 460 & 39.5 & 21.7 \\
F-POSS & 342 & 426 & 23.0 & 13.1 \\
PHEMA & 231 & 363 & 0.5 & \\
PHEMA/OH-POSS & 231 & 377 & 8.6 & \\
PHEMA/G-POSS & 230 & 367 & 6.0 & \\
PHEMA/F-POSS & 232 & 369 & 2.5 & \\
\hline
\end{tabular}

(a)

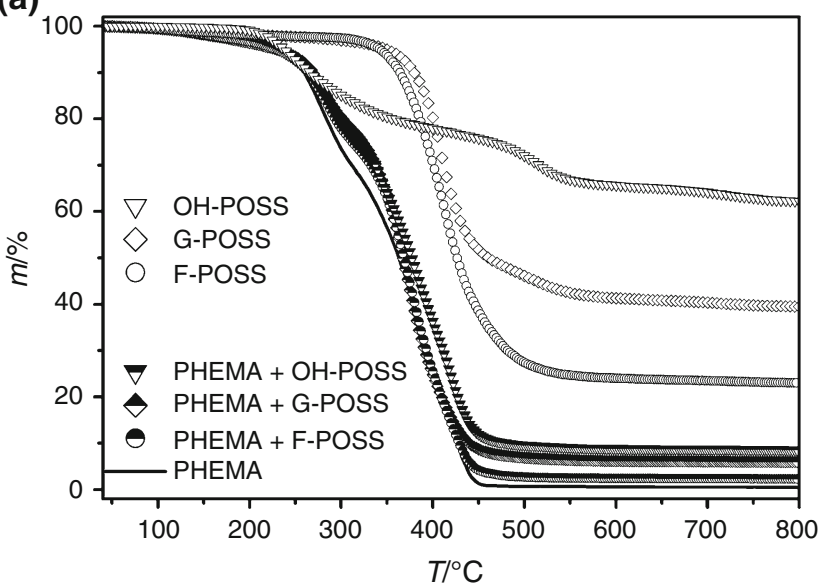

(c)

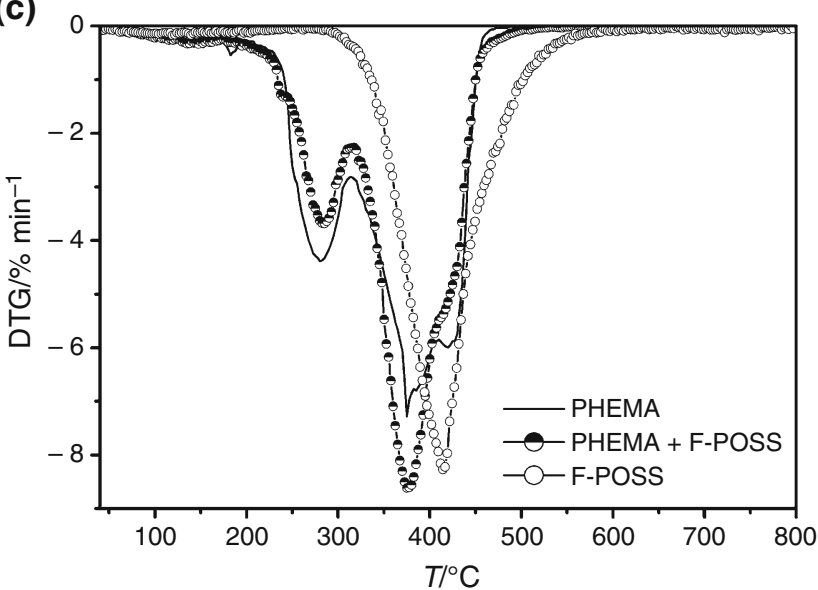

(b)

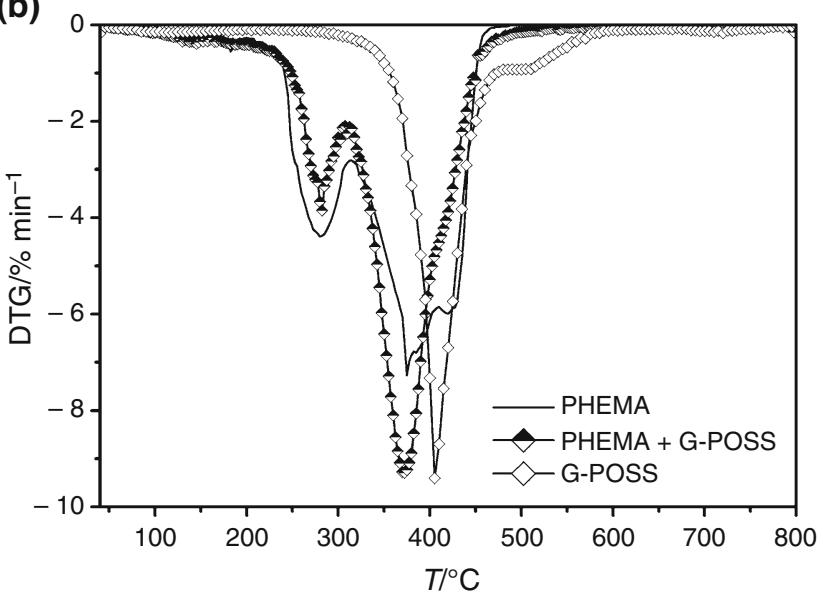

(d)

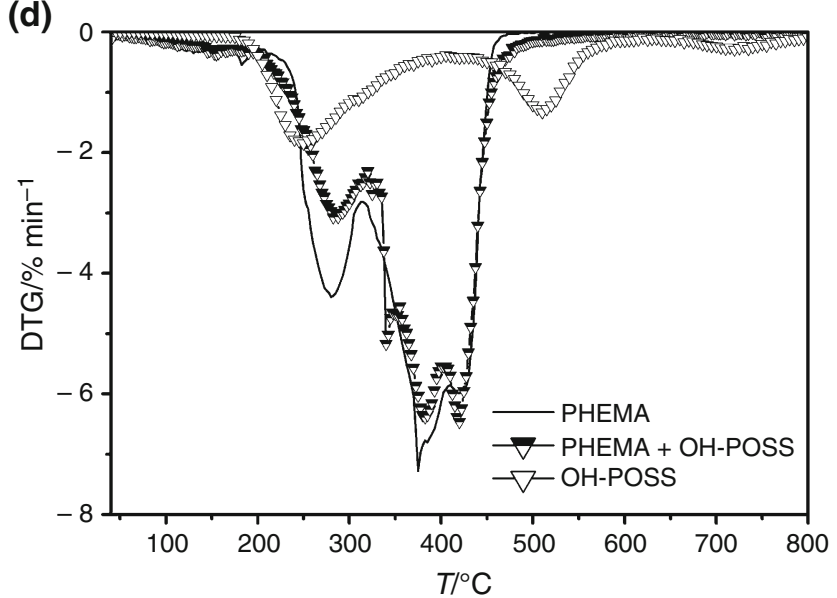

Fig. 11 TG curves of poly-HEMA, G-POSS, OH-POSS, F-POSS and their composites containing 20\% of the modifiers (a); corresponding DTG curves $(\mathbf{b}-\mathbf{d})$ 
(a)

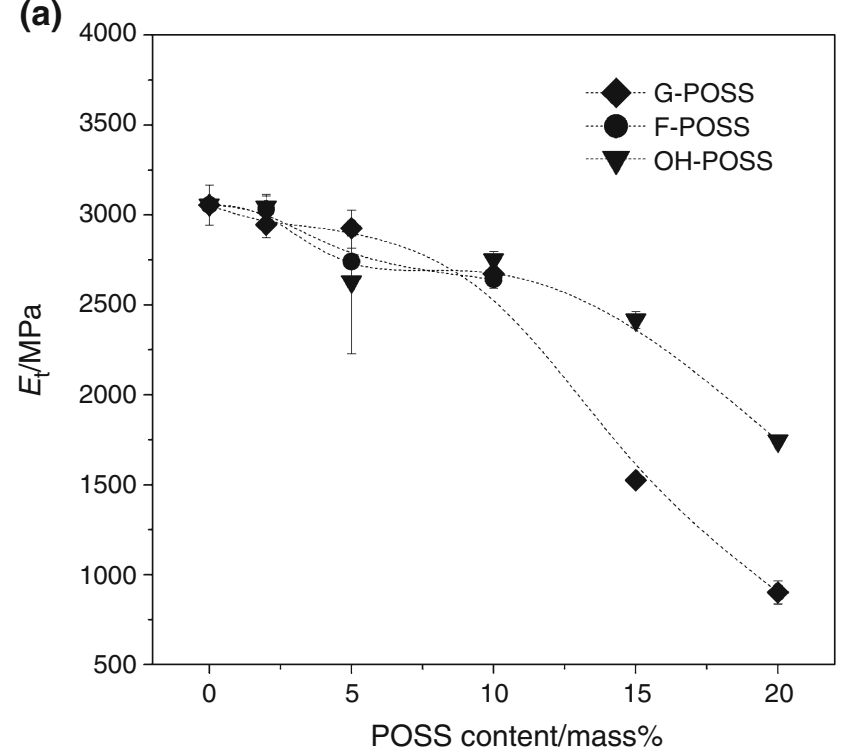

(c)

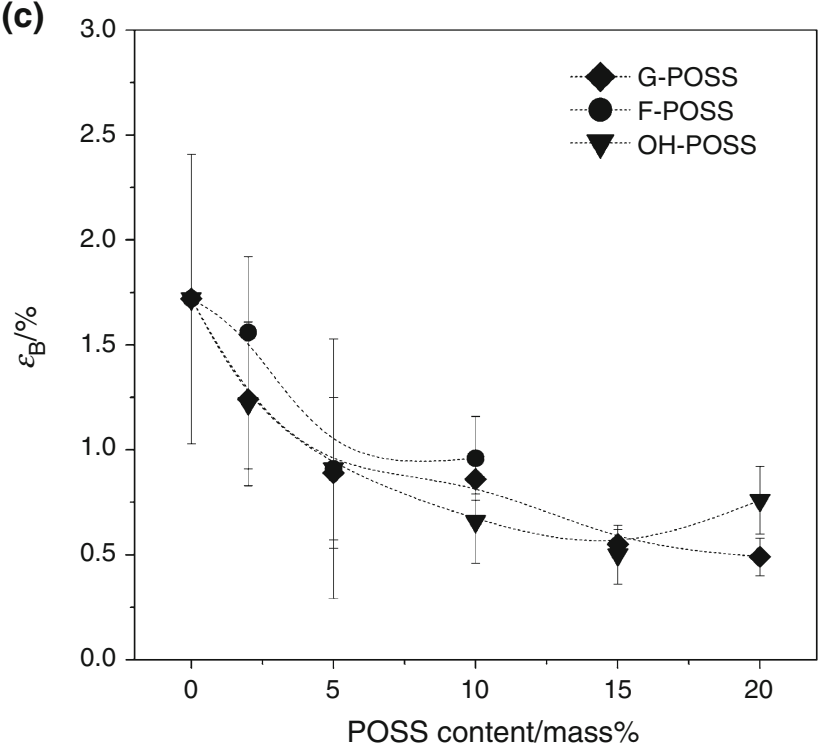

(b)

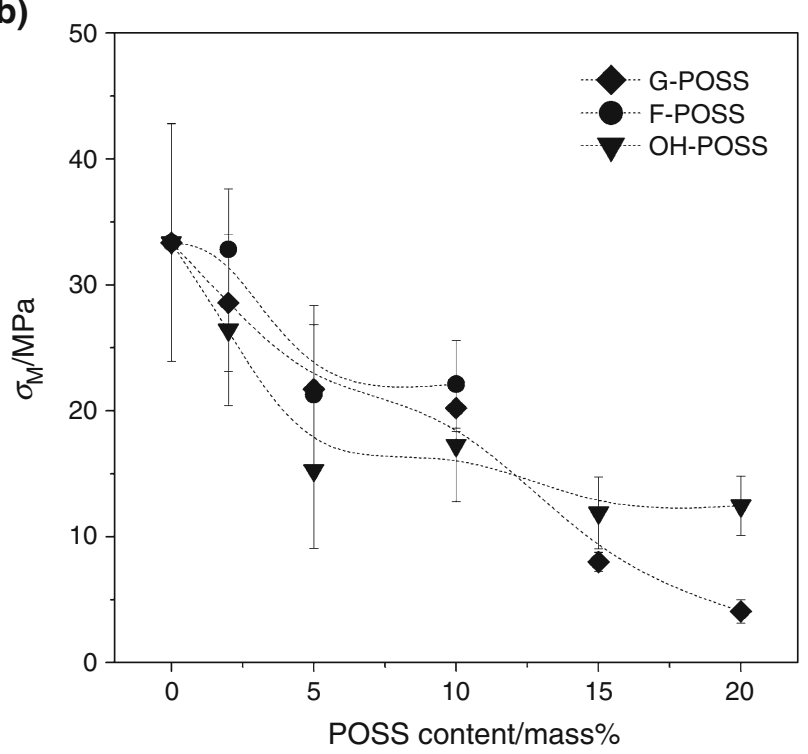

(d)

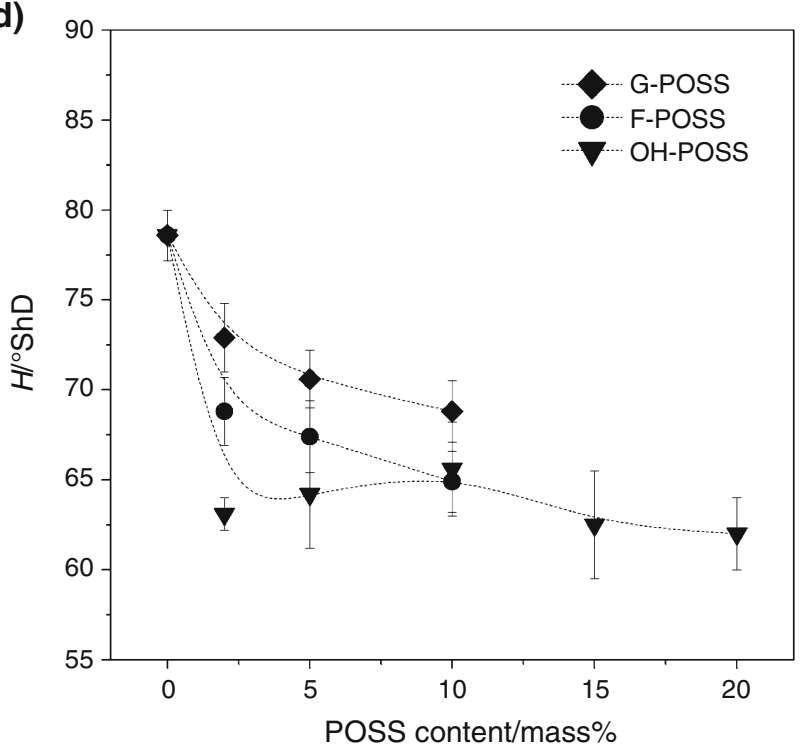

Fig. 12 Dependence of Young's modulus $E_{\mathrm{t}}(\mathbf{a})$, tensile strength $\sigma_{\mathrm{M}}(\mathbf{b})$, elongation at break $\varepsilon_{\mathrm{B}}(\mathbf{c})$ and Shore hardness $H(\mathbf{d})$ of poly-HEMA/ POSS composites on POSS content. The lines are guides to the eye

\section{Thermal stability}

The effect of the investigated POSS derivatives on the thermal stability of the poly-HEMA matrix was evaluated for composites loaded with 20 mass $\%$ of the POSS modifiers. The TG and DTG curves of neat POSS compounds, neat poly-HEMA matrix and poly-HEMA/POSS composites are shown in Fig. 11. Temperatures at $5 \%$ mass loss $\left(T_{5}\right)$, at $50 \%$ mass loss $\left(T_{50}\right)$ and residual mass $(R)$ are reported in Table 1.

Of the neat modifiers, the lowest thermal stability shows OH-POSS (three-step degradation), which is mainly associated with dehydration of $\mathrm{OH}$ groups. The thermal stability of G-POSS and F-POSS (one-step degradation) is similar and better than the stability of OH-POSS. However, in all cases, the residual mass $R$ is higher than that resulting from the mass fraction of POSS cages, which can be associated with the glassy silica layer formed during the pyrolysis of the POSS cages decreasing the diffusion rate of the decomposition gases $[25,26]$.

Introduction of modifiers into the polymer matrix does not affect markedly the beginning of the matrix decomposition (occurring in several steps associated with dehydration, depolymerization and degradation of the polymer backbone), and $5 \%$ of mass loss occurs at the temperatures very close to that observed in the case of pure poly-HEMA. 
However, the modifiers (except of OH-POSS) slow down the loss of mass during increasing temperature as is evident from the increased $T_{50}$ values. TG and DTG curves of the composites are superposition of the corresponding curves for the individual components. Thus, the nonreactive POSS have very slight influence on thermal decomposition of the poly-HEMA matrix. The protective effect exerted by POSS is manifested by the increased amounts of residual mass $R$.

\section{Mechanical properties}

The results of mechanical measurements are presented in Fig. 12. In several cases, for higher POSS loadings, the obtained materials were too brittle to determine their mechanical parameters, hence the lack of some measuring points. As can be seen, the effect of all three POSS types is very similar and leads to deterioration of mechanical properties. At low modifier concentrations, this is probably due to plasticization of the material, which can also have a positive aspect in some applications. Up to about $10 \%$ by mass of the modifier content, the stiffness of the composites (associated with the Young's modulus) decreases only slightly and this concentration appears to be the upper limit for filling the poly-HEMA with the tested nonreactive POSS derivatives. The negative effect of higher POSS loads on mechanical properties can be mainly attributed to the phase separation.

\section{Conclusions}

The effect of various amounts of three nonreactive POSS derivatives on the photo-induced polymerization of HEMA and properties of the resulting materials was investigated by DSC and TG. The HEMA/POSS systems were characterized before, during and after the photocuring, with the special emphasis on the photopolymerization kinetics.

The investigated POSS derivatives, although fully miscible with HEMA, are only partially miscible with the polymer, forming separate domains in the cured material. Thus, poly-HEMA/POSS are two-phase materials that can be considered as a type of (micro)composites. The HEMA/ POSS mixtures exhibit a viscosity synergism that may confirm the interaction between the monomer and the modifier. Although FTIR studies confirm the existence of intermolecular interactions between HEMA and OH-POSS or G-POSS, poly-HEMA/POSS interactions are insufficient to ensure full compatibility of the components in the cured material.

The dependencies $T_{\mathrm{g}}=f($ POSS content $)$ show a minimum between 2 and 5 mass $\%$ of the modifier content. At low concentrations, POSS derivatives disrupt hydrogen bonding between poly-HEMA chains and the presence of
POSS cages increases the free volume; these effects cause the plasticization of the material. Above about 5 mass\%, the separated POSS domains behave as nanofiller aggregates, introducing topological constraints and steric hindrance, which leads to an increase in $T_{\mathrm{g}}$.

The nonreactive POSS have very little effect on thermal decomposition of the poly-HEMA matrix, which can result in a degree from the phase separation. Phase separation is also the main reason of the deterioration of the mechanical properties of composites compared to a pure polymer matrix.

Nonreactive POSS derivatives significantly affect the kinetics of HEMA polymerization. They enhance the gel effect and increase the polymerization rate and the conversion of double bond. The enhancement of the gel effect is mainly associated with a substantial increase in the initial viscosity of POSS-containing formulations which leads to suppression of termination reaction (decrease in $k_{\mathrm{t}}^{\mathrm{b}}$ ). This beneficial effect intensifies with the POSS content up to 15 mass $\%$ and then begins to decrease due to possibly too large dilution of the system. Determination of the polymerization rate coefficients as function of double bond conversion for HEMA/G-POSS mixtures proved that the observed accelerating effect of G-POSS on HEMA polymerization is related to both the decrease in the $k_{\mathrm{t}}^{\mathrm{b}}$ coefficient (predominant effect, mainly due to the increase in viscosity) and to the increase in the $k_{\mathrm{p}}$ coefficient, which results from the interaction between G-POSS and the monomer. Detailed kinetic studies showed also the effect of the POSS cage, which seems to mitigate the inhibitory effect of viscosity on the diffusion of macroradicals by exerting a slip effect.

Acknowledgements This work was supported by the Polish Ministry of Science and Higher Education and the European Regional Development Fund under the Innovative Economy Operational Programme for 2007-2013, Priority 1, Action 1.3. (Project No. UDAPOIG.01.03.01-30-173/09 Nanosil). The authors thank Dr. Michal Dutkiewicz from Wielkopolska Centre of Advanced Technologies for synthesis of F-POSS, OH-POSS and G-POSS.

Open Access This article is distributed under the terms of the Creative Commons Attribution 4.0 International License (http://creative commons.org/licenses/by/4.0/), which permits unrestricted use, distribution, and reproduction in any medium, provided you give appropriate credit to the original author(s) and the source, provide a link to the Creative Commons license, and indicate if changes were made.

\section{References}

1. Lungu A, Florea NM, Manea M, Vasile E, Iovu H. Polyhedral oligomeric silsesquioxanes nanoreinforced methacrylate/epoxy hybrids. J Appl Polym Sci. 2016;133:42912. 
2. POSS ${ }^{\circledR}$ User's Guide. A guide to developing new products with POSS $^{\circledR}$ Version 2.06. https://hybridplastics.com/wp-content/ uploads/2015/04/user-v2.06.pdf. Accessed 22 Jan 2019.

3. Kuoa S-W, Chang F-C. POSS related polymer nanocomposites. Prog Polym Sci. 2011;36:1649-96.

4. Caydamli Y, Yildirim E, Shen J, Fang X, Pasquinelli MA, Spontak RJ, Tonelli AE. Nanoscale considerations responsible for diverse macroscopic phase behavior in monosubstituted isobutyl-POSS/poly(ethylene oxide) blends. Soft Matter. 2017;13:8672-7.

5. Yuasa S, Sato Y, Imoto H, Naka K. Fabrication of composite films with poly(methyl methacrylate) andincompletely condensed cage-silsesquioxane fillers. J Appl Polym Sci. 2018;135:46033.

6. Kodal M, Sirin H, Ozkoc G. Effects of reactive and nonreactive POSS types on the mechanical, thermal, and morphological properties of plasticized poly(lactic acid). Polym Eng Sci. 2014;54:264-75.

7. Sarkar B. POSS-containing polyamide-based nanocomposites. In: Kalia S, Pielichowski K, editors. Polymer/POSS nanocomposites and hybrid materials. Preparation, properties, applications. Cham: Springer; 2018. p. 205-33.

8. Blanco I, Abate L, Antonelli ML, Bottino FA, Bottino P. Phenyl hepta cyclopentyl-polyhedral oligomeric silsesquioxane ( $\mathrm{ph}$, hcp-POSS)/Polystyrene (PS) nanocomposites: the influence of substituents in the phenyl group on the thermal stability. eXPRESS Polym Lett. 2012;12:997-1006.

9. Andrzejewska E. Photopolymerization kinetics of multifunctional monomers. Prog Polym Sci. 2001;26:604-65.

10. Johnson PM, Stansbury JW, Bowman CN. Photopolymer kinetics using light intensity gradients in high-throughput conversion analysis. Polymer. 2007;48:6319-24.

11. Przadka D, Andrzejewska E, Marcinkowska A. Multimethacryloxy-POSS as a crosslinker for hydrogel materials. Eur Polym J. 2015;72:34-49.

12. Dutkiewicz M, Maciejewski H, Marciniec B. Functionalization of polyhedral oligomeric silsesquioxane (POSS) via nucleophilic substitution. Synthesis. 2009;12:2019-24.

13. Szubert K, Marciniec B, Dutkiewicz M, Potrzebowski MJ, Maciejewski H. Functionalization of spherosilicates via hydrosilylation catalyzed by well-defined rhodium siloxide complexes immobilized on silica. J Mol Catal A Chem. 2014;391:150-7.

14. Singh V, Tiwari KK, Singh VK. Theoretical predictions of viscosity of binary and ternary liquid mixtures at $298.15 \mathrm{~K}$. Asian J Chem. 2008;20:4173-84.

15. Heintz A, Klasen D, Lehmann JK. Excess molar volumes and viscosities of binary mixtures of methanol and the ionic liquid
4-methyl-N-butylpyridinium tetrafluoroborate. J Solut Chem. 2002;31:467-76.

16. Odian G. Principles of polymerization. Hoboken: Wiley; 2004.

17. Morita S, Kitagawa K, Ozaki Y. Hydrogen-bond structures in poly(2-hydroxyethyl methacrylate): infrared spectroscopy and quantum chemical calculations with model compounds. Vib Spectrosc. 2009;51:28-33.

18. Coates J. Interpretation of infrared spectra, a practical approach interpretation of infrared spectra, a practical approach. In: Meyers RA, editor. Encyclopedia of analytical chemistry. Chichester: Wiley; 2000. p. 10815-37.

19. Silverstein RM, Webster FX, Kiemle DJ. Chapter 2-infrared spectroscopy. In: Silverstein RM, Webster FX, Kiemle DJ, editors. Spectrometric identification of organic compounds. 7th ed. Hoboken: Wiley; 2005. p. 72-126.

20. Andrzejewska E. Termination mechanism in photoinitiated radical crosslinking polymerization. In: Pandalai SG, editor. Recent research developments in polymer science, vol. 7. Trivandrum: Transworld Research Network; 2003. p. 247-70.

21. Sadej-Bajerlain M, Gojzewski H, Andrzejewska E. Monomer/modified nanosilica systems: photopolymerization kinetics and composite characterization. Polymer. 2011;52:1495-503.

22. Lee TY, Roper TM, Jonnson ES, Guymon CA, Hoyle CE. Influence of hydrogen bonding on photopolymerization rate of hydroxyalkyl acrylates. Macromolecules. 2004;37:3659-65.

23. Andrzejewska E, Marcinkowska A, Prządka D, Kloziński A, Jakubowska P. Polymeric hybrid and composite materials containing functionalized polyhedral oligomeric silsesquioxanes (POSS). Polimery/Polymers. 2013;58:794-804.

24. Kim D-G, Sohn H-S, Kim S-K, Lee A, Lee J-C. Star-shaped polymers having side chain POSS groups for solid polymer electrolytes; synthesis, thermal behavior, dimensional stability, and ionic conductivity. J Polym Sci Part A Polym Chem. 2012;50:3618-27.

25. Markovic E, Clarke S, Matisons J, Simon GP. Synthesis of POSSmethyl methacrylate-based cross-linked hybrid materials. Macromolecules. 2008;41:1685-92.

26. Wang Y, Liu F, Xue X. Synthesis and characterization of UVcured epoxy acrylate/POSS nanocomposites. Prog Org Coat. 2013;76:863-9.

Publisher's Note Springer Nature remains neutral with regard to jurisdictional claims in published maps and institutional affiliations. 